\title{
TECHNOLOGY-DRIVEN INNOVATIONS IN FINANCIAL SERVICES: THE RISE OF ALTERNATIVE FINANCE
}

\author{
Lech GĄSIORKIEWICZ*, Jan MONKIEWICZ**, Marek MONKIEWICZ*** \\ *Warsaw University of Technology, Faculty of Management, Warsaw, POLAND \\ e-mail: lech.gasiorkiewicz@pw.edu.pl \\ **Warsaw University of Technology, Faculty of Management, Warsaw, POLAND \\ e-mail: j.monkiewicz@onet.eu \\ ***Main School of Commerce, Institute of Risk and Insurance, Warsaw, POLAND \\ e-mail: marekmonkiewicz@o2.pl
}

\begin{abstract}
Financial systems worldwide are increasingly experiencing the mounting pressure of the technology-based financial innovations. Some of these developments are generating alternative financial structures existing parallelly to the "old" ones, whereas some others are simply replacing the "old" ones. Alternative intermediating institutions are gaining ground vis-à-vis incumbents, relying on their technological and market supremacy. The space of traditional financial intermediation requires new solutions to be more competitive. Some technological solutions provide additionally for the partial or entire disintermediation of the financial services, thus removing some existing transaction costs and matching directly economic agents. Digitalization and datafication, coupled with artificial intelligence, are offering immense new operational opportunities and economic benefits. On the other hand, they are also the source of new risks to the financial and economic systems, financial stability, national security, and consumer well-being, which need to be properly addressed. We review in this paper principal components of the current stream of technology-based financial innovations and their main drivers, as well as discuss major strategic issues and impacts that we are facing in this area.
\end{abstract}

Keywords: alternative finance, financial innovations, FinTech, technology enablers, digitalization, financial consumer protection.

JEL Classification: G21, G22, G23.

\section{Introductory observations}

Financial innovations are nothing new in financial development. They have already had a long history, to recall introduction of a double-entry book keeping, establishment of modern central banking, application of fiat-based monetary system, development of local and international payment systems, invention of securitization, collateralized debt obligation (CDO), or parametric insurance.

The same is true with the application of technological enablers to financial innovations. Let us remind in this context the role played by the development of telecommunication, in particular, the telephone and telegraph, for the financial services, application of ATM, or diffusion of high-frequency trading.

What is new, however, since the last 10 years or so is the accelerated pace of technological innovations based on the use of computers and digitalization.
They find their application in financial services and markets, and their societal and economic weight is dramatically increased. They are producing ever deeper structural changes in the entire financial system. With the rise of new technology, there is the clear switch from analog to digital world.

Innovations in financial systems and financial services did not attract particular public attention either among researchers or among the policy makers before the outbreak of global financial crisis in 2007. By then, they were considered to be the useful and non-controversial component of the financial system, providing, inter alia, more flexibility to established rules, reducing agency costs, completing the markets, allowing for better risk distribution in the financial sector, and improving its allocative efficiency. This traditional positive approach to financial innovations was associated with the then dominance of innovation-growth proponent school, which considered 
innovations as an engine of growth. This view was contested after the outbreak of the crisis by the innovation fragility school, which was identifying financial innovations as the root cause of the global financial crisis, and thus, at times, detrimental to the economic development processes (Beck, et al., 2012).

The driving force in place was the possibility of unprecedented credit growth made available with the application of innovative structured security products: mortgage-backed securities (MBSs), credit default swaps (CDSs), and CDOs in particular. This led finally to the unusual boom and bust in the US housing market (Henderson and Pearson, 2011; Brunnermeier, 2009; Calomiris, 2009).

Since then, these two approaches are coexisting, with an obvious conclusion that innovations may deliver both dark as well as bright results. They are inherently risky and may bring individual households, companies, and financial institutions to impairment or failure and the whole economy to financial instability. Their influence resembles one of those medicines which may be dangerous if taken by the wrong patients in wrong time or in wrong doses. Therefore, it is a complex task for the policy makers how to reduce the possible negative outcomes of financial innovations while preserving their merits (WEF, 2012; Halliasos, 2013).

In our paper, we do not enter this complex and controversial area. We simply acknowledge the existence of different views and approaches. Instead, we concentrate on sketching the contours of the current situation with regard to the spread of financial innovations in the financial systems and the opportunities and challenges they generate.

We see the role of financial innovations in a positive way, as making financial markets more complete, more effective, and more efficient for the households, companies, and governments. Their important task is also making financial intermediaries themselves more effective and more efficient. In the course of the discussion, we underline the fact that they are not risk free and may produce unwanted effects.

In this paper, we intend to review the principal components of the current stream of innovations, its basic drivers, and the major strategic issues that we are facing in this area and their implications.

We argue that the current wave of financial innovations, induced largely by the application of technology enablers, has the potential of disrupting financial systems and financial services that we know. It refers to the products on offer, new structure of universe of financial services providers, role of third-party services suppliers, governance of the whole financial system, and the challenges of the new risks as well as the old risks in a digitized environment. Finally, it is also the way consumer interests are to be protected.

We look at some of them in a highly synthetic and holistic way. We begin with some definitional clarification and thereafter touch the selected aspects of the development in the area in quest ${ }^{1}$.

\section{Taxonomy of financial innovations}

There are no universally accepted definitions of financial innovations. Nor is there any universally accepted systematics of the phenomenon. The issue was addressed for the first time at a global level by the Bank for International Settlements (BIS) way back in 1986. It was then that a specially established study group of the central banks attempted to propose a systematization of financial product innovations in the banking area (BIS, 1986). The group prepared a broad study in which it proposed a classification system for financial innovations.

In its proposal, they were split into three groups:

- risk-transferring innovations, which either reduce the price risk/credit risk, inherent in a particular financial instrument, or alternatively, enable the holder to protect against a particular risk,

- liquidity-enhancing innovations, which enable loans to be sold in a secondary market which offers the lending institution the capacity to change the structure of its portfolio, and

- equity-generating innovations, which have the effect of giving an equity characteristic to assets

\footnotetext{
${ }^{1}$ For more clarification see: Gasiorkiewicz, L., Monkiewicz, J., 2021 (forthcoming).
} 
where the nature of the debt-servicing commitment is predetermined, for example, a debt-equity swap (Mishra, 2008).

This useful attempt of BIS has not been developed further, and thus, systematization of financial innovations in international community has not been advanced thereafter. Various studies and approaches of individual researchers have not acquired universal acceptance and not produced any meaningful standard for use. This, of course, hampers the development of empirical studies and comparability of the registered results across time, territory, or area. Hence, analytically, today we are more in the situation of individual studies at a micro level than otherwise. It should be noticed perhaps that here, the research field with respect to innovations is far behind the state-of-art respective traditional industries. There, the intellectual property system, in particular, the patenting system provides ready-for-use, widely comparable data and information. Financial industry has not come this far yet.

Traditionally, the concept of innovations was applied to the introduction of changes in technology, techniques, and organizational solutions for the production processes taking place in the economic systems.

Originally, the concept became widely popularized in economic sciences by J. A. Schumpeter, a renowned Austrian economist, at the beginning of the 20th century (Schumpeter, 1934). He claimed that it is precisely innovation creation which constitutes the essence of entrepreneurship and the social reason for the existence of entrepreneurs. It was contrary to the belief widely held before his arrival that it was their ability to create profits and reproduction of the capital.

Schumpeter not only provided theoretical base for the study of the role of innovation in the process of economic development, but also introduced a specific systematics in this regard. It began to be used later by the international community to distinguish the four principal classes or types of technical innovations (OECD, 2018). They included product innovations, process innovations, marketing innovations, and organizational innovations. It was also applied for the creation of specialized statistical database covering technical innovations in the world run by the Organisation for Economic Co-operation and Development (OECD). The Oslo Manual, which became a central international document in this regard, provided detailed explanations regarding typology of innovations, repeating the principal ideas of Schumpeter.

Thus, it defined product innovation as the introduction of a good or a service that is new or significantly improved. This includes significant improvements in technical specifications, components, and materials, incorporated software, user friendliness, and other functional characteristics.

Process innovation is defined as the implementation of a new or significantly improved production or delivery method. This includes significant changes in techniques, equipment, and/or software.

Marketing innovation is defined as the implementation of new marketing methods involving significant changes in product design or packaging, product placement, product promotion, or pricing.

Finally, organizational innovation is defined as the implementation of new organizational methods in the firm's business practices, workplace organization, or external relations (Oslo Manual, 2018).

As far as financial innovations are concerned, generically, this term is used for the description of the ongoing process of changes taking place in the financial systems, covering a variety of elements, including financial services, financial markets, financial products, financial institutions, financial supervisors, financial infrastructure, and, last but not least, financial regulations. They may represent the defined changes on a standalone basis or, which is, by and large, more frequent situation, they may interact with each other. It is for these reasons that financial systems belong to complex objects and financial innovations add to their complexity and produce additional challenges.

We will use this generic understanding of financial innovations throughout our paper without going deeply into the semantic discussion. We believe that intuitive understanding is a more pragmatic solution for our analysis. 


\section{$3 \quad$ Main drivers of current financial innovations}

Financial innovations, in general, respond to the needs of the users of the financial systems and the opportunities available to their stakeholders, both the financial institutions, regulators, as well as the economic agents, including the customers. What is especially visible nowadays is that financial innovations are under a growing pressure of new technologies developed few years ago or still upcoming. These new technologies transform the shape and the way financial systems are operating and the financial services that are provided.
These new technologies have their roots in the development and spread of internet and the digitalization and datafication of social and economic life.

This wave of financial innovations is referred to as FinTech and is most frequently defined as "technology-enabled financial innovation that could result in new business models, applications, processes or products with an associated material effect on financial markets and institutions and the provision of financial services" (FSB, 2017, p.7).

BIS and specifically its associated Financial Stability Institute (FSI) recently proposed a useful systematization of the relevant area in the form of FinTech tree. It split the FinTech environment into three distinct parts: FinTech activities, enabling technologies, and enabling policies (see Fig.1).

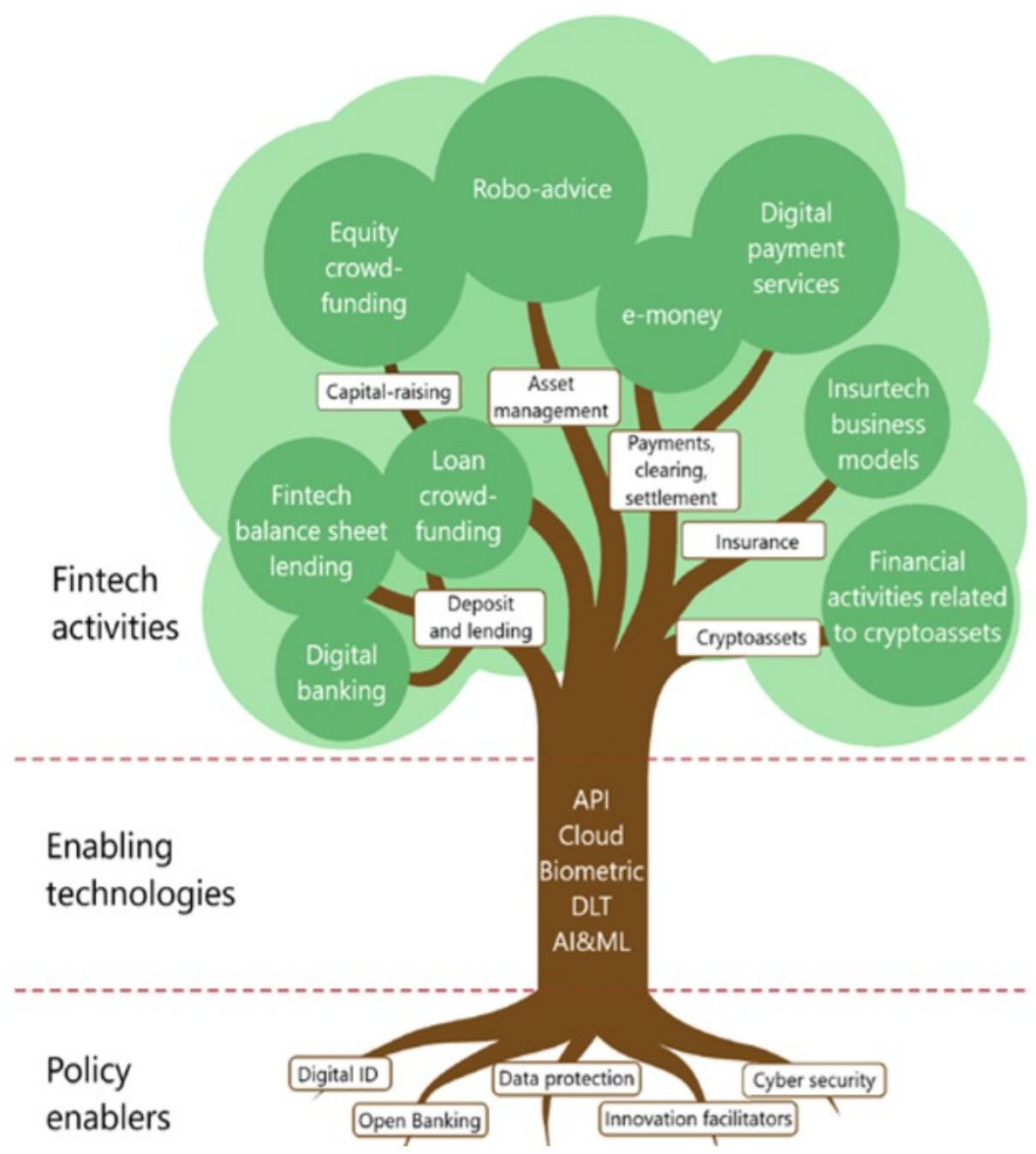

Figure 1. FinTech tree: a taxonomy of the FinTech components

(Source: BIS, 2020, p.7) 
Among the recent FinTech activities, one could mention particularly digital banking and loan crowdfunding, capital raising, telematics and internet of things in insurance, robo advice in asset management, issuance of cryptoassets, and e-wallets and digital payment systems. We should not forget the digital infrastructure facilities as well. Of course, this list is only exemplary and is evolving continuously.

Among technology enablers, we should mention particularly artificial intelligence and machine learning, distributed ledgers technology, biometric-based identification and authentication, big data and cloud computing, and, last but not least, application programming interfaces that enable cooperation of various financial applications at the same time.

Last but not least, there are the policy enablers of FinTech that principally entail relevant regulatory solutions and physical infrastructural elements. They provide the base and the framework for FinTech activities. They rest primarily on the shoulders of national states. They may entail, for example, creation of a proper national broadband internet network, development of digital authentication systems, defining the data protection rules and systems, and finally, addressing the cybersecurity issues.

\section{$4 \quad$ Financial services providers and FinTech}

FinTech developments facilitate new entrants' arrival into the financial system, which have the potential of changing its composition, concentration, organization, and the modus operandi.

They comprise at least three distinct classes of entities (FSB, 2019, pp.2-5).

The first class is composed of the FinTech companies themselves - bank-like or insurance-like or asset-like companies - which rely on their The information and communication technology (ICT) technological supremacy in some areas and may offer financial services in selected areas on their own, competing against existing incumbents. This is by far the most populous fraction of newcomers, bringing more diversity, volatility, and competition to financial services provision. They also bring additional risks from the regulatory standpoint as well as have market stability implications due to their competitive pressure on financial institutions' margins. Their population is difficult to measure precisely as they lack a precise definition. According to a study conducted by the European Parliament in 2018, FinTechat that moment, the global FinTech sector was made up of circa 3800 companies. Around 1500 of them were domiciled in the USA, 1000 were registered in the European Union (EU), 250 were in India, and about 100 were in China (European Parliament, 2018, p.33).



Figure 2. Financial services in Big tech portfolio

(Source: BIS, 2019, p.56) 
The second class of entities consists of the Big tech companies which are most commonly defined as large technology-based entities whose primary activities encompass provision of digital services. Financial services are, unlike in FinTech companies, their secondary product so far. It is estimated that Big tech revenues in 2018 were coming primarily from communication services (above 46\%), and only around $11 \%$ represented revenues from financial services.

Financial services in Big tech portfolio are presented in Fig. 2.

The population of Big tech companies in comparison to FinTech entities is very limited, and global players include mainly American and Chinese corporations currently. We could mention here in terms of example the names of Alibaba, Amazon, Apple, Baidu, Facebook, Google, Microsoft, Samsung, and Tencent.
The core business of these companies is information technology, and the business model of these companies rests on providing for direct interactions among a large number of users. Side effects of their business activities are established customer data and networks and advanced software development.

The future competitive impact of Big tech on the financial services market may be substantial. With their established customer networks and name recognition, technological lead, as well as strong financial position, they could become a real challenge to the existing incumbents. To put it into the financial perspective, available statistics indicate that in 2019, stock market capitalization of the first seven largest Big tech has surpassed by far the stock market capitalization of the seven largest financial groups in the world (see Fig. 3).

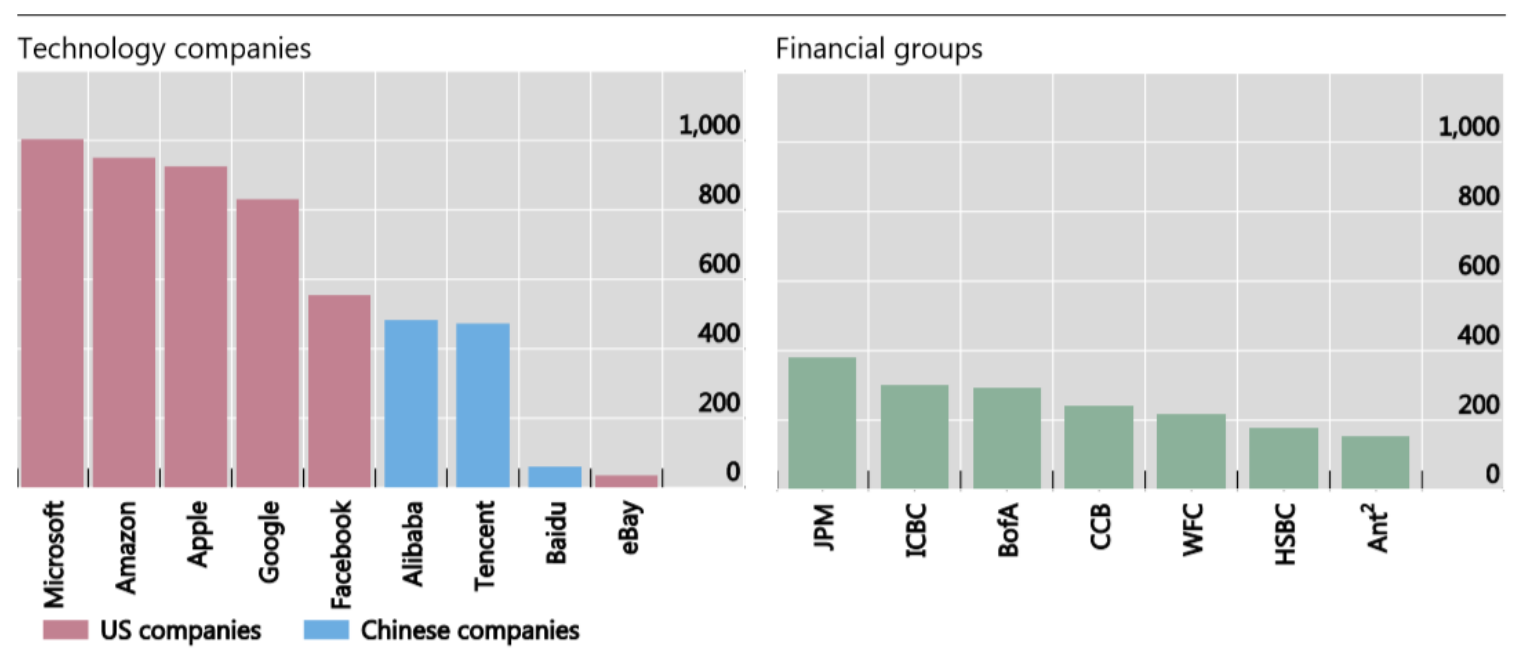

Ant = Ant Financial; BofA = Bank of America; $C C B=$ China Construction Bank; ICBC = Industrial and Commercial Bank of China; JPM = JPMorgan Chase; WF = Wells Fargo. ${ }^{1}$ Stock market capitalisation, 30 April 2019. ${ }^{2}$ The estimated value of Ant Financial was derived from the amount raised in the company's recent funding rounds. Sources: Thomson Reuters Eikon; hurun.net; company reports.

Figure 3. Stock market capitalization of Big tech versus major financial groups (Source: FSB, 2019, p.4)

The first Big tech on the list - Microsoft - has recorded a market capitalization 2.5 times higher than J. P. Morgan, the leader of the financial institutions list (FSB, 2019, p.4)

The third population of entities consists of the ones that are composed of third-party service providers to the world of financial institutions and their role is quickly growing. A part of them currently belong to Big tech and another part to FinTech companies. New emerging trend is the presence of governmentsponsored establishments here, which reflects growing security concerns and the search for national digital sovereignty.
Financial institutions rely on third-party service providers, inter alia, for data provision, physical connectivity, and cloud services. Particularly relevant today are cloud computing services.

Cloud computing refers in principle to the practice of using a network of remote servers, typically accessed over the internet, for the provision of IT services. It offers more convenient and frequently costeffective access to computing resources compared to the in-house approach. Principal advantages are economies of scale, flexibility, operational efficiencies, and cost-effectiveness. 
The overall spending of financial institutions on cloud services is estimated to reach the level of $\$ 55$ billion in 2020, up from $\$ 37$ billion in 2017 (Gartner, 2017).

The service could be offered in different constellation and different business models (US Department of Treasury, 2018, pp.44-47). It should be noted perhaps that as of now, outsourcing services in cloud computing for financial sector entities are in most cases subject to regulatory consent. Traditional IT compared to cloud computing is presented in Fig. 4.

\section{Traditional IT Compared to Cloud Computing}



Figure 4. Traditional IT compared to cloud computing (Source: US Department of Treasury, 2018, p.46)

Cloud computing is strongly associated with the big data issue. Technological advances lead to increasing amounts of data collected, processed, shared, and used in digital form at a lower cost and on a larger scale. Big data generally refers to technological developments related to the area of data collection from various sources, storage, processing, verification, analysis, and applications. It is often characterized by the increased volume, velocity, and variety of data being produced. It typically refers to data coming from the internet, but of course is not limited to them (EBA, 2020, p.12).

Big data offers particular advantages when processed with the advanced analytics tools, that is, with the autonomous examination of data or content using sophisticated artificial intelligence techniques.

Advanced analytics techniques, based on artificial intelligence, may include a number of tools like text mining, machine learning, forecasting, visualization, semantic analysis, sentiment analysis, network examination of data or content, etc.

This may assist in forecasting the future behavior of financial market participants, while transaction analysis may help in detecting some repetitive patterns. This may lead to the development of the technology of smart contracts and their automatic self-execution, when ex ante defined conditions are met. This may result in lowering the total transaction costs and acceleration of its implementation.

Nowadays, big data analytics seem to be particularly well developed in the insurance sector which has a long tradition and a strong demand for the use of statistics for business purposes, including underwriting policies, claims settlement, or fraud detection.

In the recent thematic study of European Insurance and Occupational Pensions Authority (EIOPA) on the use of big data analytics in medical and motor insurance in the EU, it was revealed that traditional data 
sources such as demographic data, loss data, hazard data, mortality, and morbidity rates are to a growing degree supplemented with other data coming from car telematics, internet of things, social media exploration, web searches, and web comparators, data generated from third-party vendors, bank accounts data, or health genetic data (EIOPA, 2019, p.12-13).

It creates a completely new reality for the insurance companies and their risk assessment possibilities, applied business models, and market pricing.

Progress in big data analytics is closely linked with the digitalization and datafication of economic and social life, as well as the development of artificial intelligence and its important component, machine learning. Particularly, advantages are offered by natural language-processing technologies that allow for automatic processing of factual texts.

Machine learning provides systems the ability to automatically learn and improve from experience without being explicitly programmed. Deep learning, on the other hand, is a subset of machine learning, which uses the neural networks to analyze different factors with a structure that is similar to the human neural system. It is particularly useful for the analysis of unstructured data. Fig. 5 presents the field of Artificial intelligence (AI) and its interactions with Machine learning (ML) and Big Data analytics.

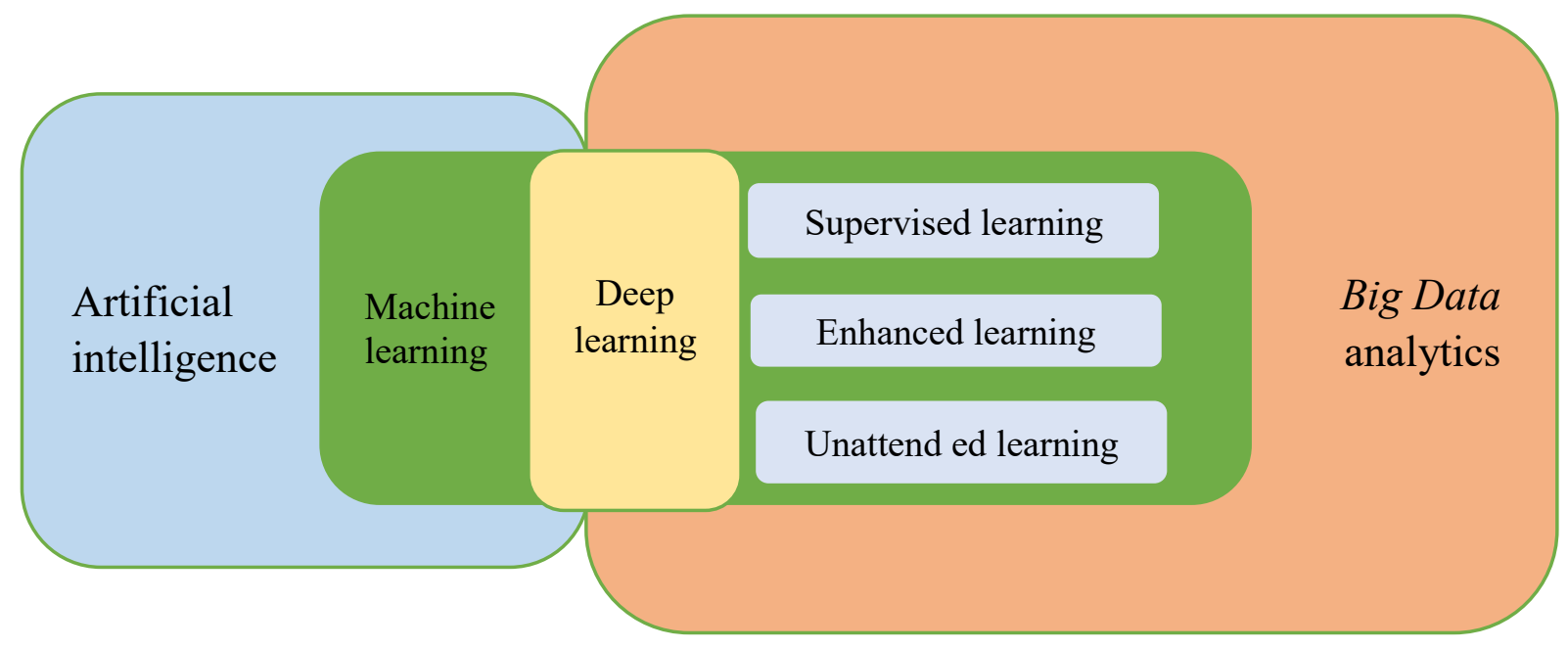

Figure 5. Interactions between AI, machine learning, and Big Data analytics (Source: Kabza, 2020)

There are three major recognized categories of machine learning: supervised learning, unsupervised learning, and reinforcement learning, depending on the human involvement into the process.

Artificial intelligence is concurrently generating high level of start-up activities and is becoming increasingly an object of geostrategic competition worldwide. Potential impact of this innovation on global economy is estimated to reach the level of 13-16 billions of US dollars by 2030 (EU Monitor, March 2020).

\section{Financial innovations and the governance of the financial systems}

Financial innovations are not only impacting the composition of intermediating institutions offering financial services, but are also providing a possibility of decentralizing financial systems by eliminating or reducing the need for intermediating activities or centralized processes in the delivery of financial services.

They are also effectively questioning the future role of the central banks and their monetary policy. In practice, this means a democratization of the whole system and growth of mutual reliance of the market participants on their own actions and decisions.

From the systemic point of view, there are different types of decentralization in financial services which may effectively take place. In principle, it may take three broad forms (FSB, 2019a):

- Decentralization of decision-making, which involves a move away from a single trusted financial intermediary or infrastructure. Their powers are taken by systems in which a set of users is able to make decisions about the relevant financial 
transactions. Distributed ledger technology (DLT) is a good example of the situation.

- Decentralization of risk taking, which involves the shift from the retention of risk on the balance sheets of individual financial intermediaries toward direct matching of individual users and providers of financial services. Peer to peer (P2P) services or crowdfunding may be quoted as an example.

- Decentralization of record keeping, which involves a move away from centrally held data and records toward systems in which the ability to store and access data is given away to a broader group.

There are currently two leading technologies effectively enabling decentralization of the financial systems: DLT, or blockchain, and online P2P platforms (FSB, 2019a).

DLT enables decentralization of record-keeping and processing by organizing a network of cooperating computers, governed consistently by the adopted rules. Online P2P or user-matching platforms allow users to interact directly and decentralize their risktaking and decision-making.

A vital component of decentralized finance is cryptocurrencies. Bitcoin was the first currency that was not issued by any country, but through a decentralized technology. It led essentially to the situation in which central banking is considering a number of innovations in their activities, including introduction of their own digital currencies.

Traditionally, financial institutions used to play an important role in the economy by reducing transaction costs, connecting market participants, and spreading the risk. Application of DLT and online P2P platforms is creating an entirely new situation in this respect.

They can eliminate the need for intermediaries to facilitate financial transactions. Financial system becomes decentralized, while it reduces the use of centralized institutions and processing and replaces them with decentralized autonomous networks.

Decentralized finance may signal the beginning of a shift away from industrial era finance, based predominantly on big centralized financial institutions and systems, which remained basically unchanged in the last centuries (Lippel, 2019). We are heading nowadays into the new era of network-based finance. Diffused and decentralized financial systems may be dominating the scene because of the advancement of the new technology.

\section{Cybersecurity and data protection: new risks and challenges}

Financial innovations enabled by FinTech related to the digitalization and datafication of financial activities are introducing important changes into the current risk agenda. Cybersecurity, data protection, and technological risks are coming to the front of the risk agenda in financial systems (Buckley, et al., 2019, p.1).

Cyber risk in a wide sense refers most often to the risk of financial losses, disruption, or reputational damage to the organization resulting from the failure of IT systems. Most dangerous are cyberattacks where the harm is done intentionally (BIS, May 2020).

Financial institutions are relying today broadly on digital assets, and financial services are among the most digitized sectors of the economy (Gandhi, et al., 2018).They are, therefore, highly exposed to cyber risk and cyber incidents. The financial services sector also owns a lot of sensitive personal information, which makes it a highly attractive sector for data breaches.

Cybersecurity incidents are growing in severity and frequency. As indicated by a recent study of the IMF (2020)the number of incidents recorded worldwide in the financial services has tripled in the last 10 years, and judging from a Singapore experience, they are affecting various parts of the financial sector, particularly banks and securities (IMF, 2020).

Frequency of cybersecurity incidents in finance (number of events) is presented in Fig. 6.

Recently recorded cybersecurity incidents have raised the public profile and public interest in this area. The most publicized cyberattacks globally are WannaCry and NotPetya. The WannaCry ransomware attack of 2017 affected computer systems in more than 150 countries, while the most destructive cyberattack in financial terms until now has been NotPetya, which cost at least US\$10bn (IMF, 2020, p.4). 


\section{Advisen: Cybersecurity Incidents $/ 1$}

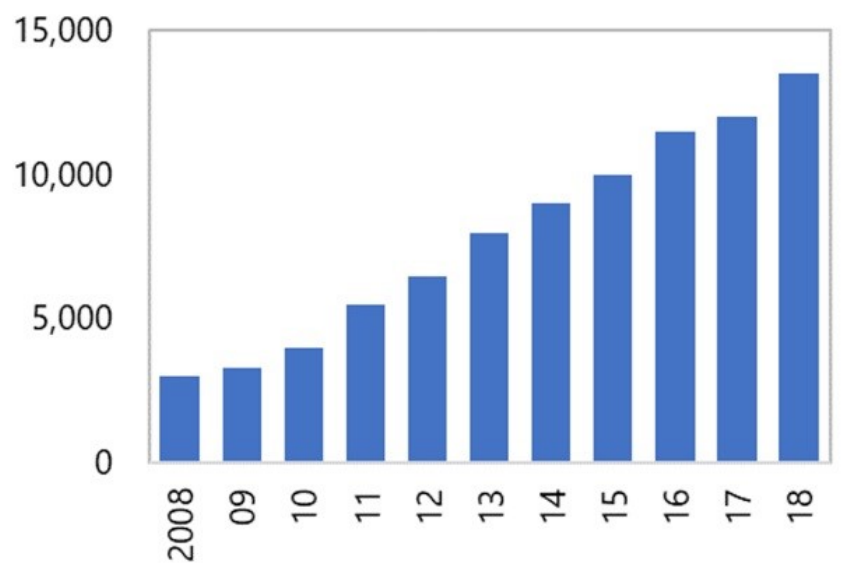

Figure 6. Frequency of cybersecurity incidents in finance (number of events)

(Source: IMF, 2020, p.15)

Note: ${ }^{1}$ Number of cybersecurity incidents from international data collected by Advisen and approximately transcribed from the Bank of Canada's 2019 Financial System Review.

Cybersecurity risk could be regarded as a new form of traditional risk related to economic crime, espionage, and service disruption, and as an entirely new form of risk (Buckley, et al., 2019, pp.9-11). It is indicated that cyber risk is emerging as the new source of financial systemic risk and therefore needs to be monitored by relevant financial regulatory authorities.

Cyber events can be classified into different types, depending on the harm that they cause. First, theft-related cyberattacks extract items such as funds, monies, customer credentials, intellectual property, or market-valuable information. Second, disruptionrelated cyberattacks endanger business functionality. Third, cyberattack can also affect data integrity, or damage system hardware or software (IMF, 2020).

With respect to financial institutions, successful cyberattacks can cause them to experience various microprudential risks, including solvency, liquidity, and market, operational, legal, and reputational risks.

Apart from microprudential risks for individual financial institutions, cyber events can also diffuse these risks through the entire financial system and cause systemic risk. This could be developed through different transmission channels such as risk concentration, risk contagion, and risk of loss of confidence (IMF, 2020, pp.8-9).

The first one arises when a cyberattack affects a key financial market infrastructure, important cloud services provider, or systemically important financial institution. This could lead to the loss of critical services that could not be easily substituted or replaced. Cyber risk and systemic risk are presented in Fig. 7.

The second one takes place when a cyberattack on a financial institution leads to financial difficulties that spill over to other financial institutions. The third one comes in a situation wherein a widespread attack triggers a loss of confidence across several financial institutions or the financial system, which endangers overall financial stability.

Additionally, datafication and digitalization of the financial services and their growing dependence on technology lead to the creation of new sources of systemic risks related to IT systems, applied algorithms (model risk), and human failure (Buckley, et al., 2019, p.19).

Last but not least, it should be stressed that new features of financial services coming from automation, usage of big data, and digitalization result in a faster movement of the risk through the financial system than in the analog world (Brummer and Yadav, 2017, p.4).

Apart from cybersecurity issues generated by the current wave of digitalization and datafication in financial services, increasingly important role relates to data security and privacy risk, which is in principle related to the proper handling of data. It refers to the issue of which data in computer systems and under what conditions could be collected, stored, processed, and shared with third parties. 
Its importance is reflected in a growing regulatory output in this regard. The most comprehensive data protection legislation enacted to date is the General Data Protection Regulation (GDPR), governing the collection, use, transmission, and security of data coming from residents of the European Union, regardless of the location of the entity collecting the data.

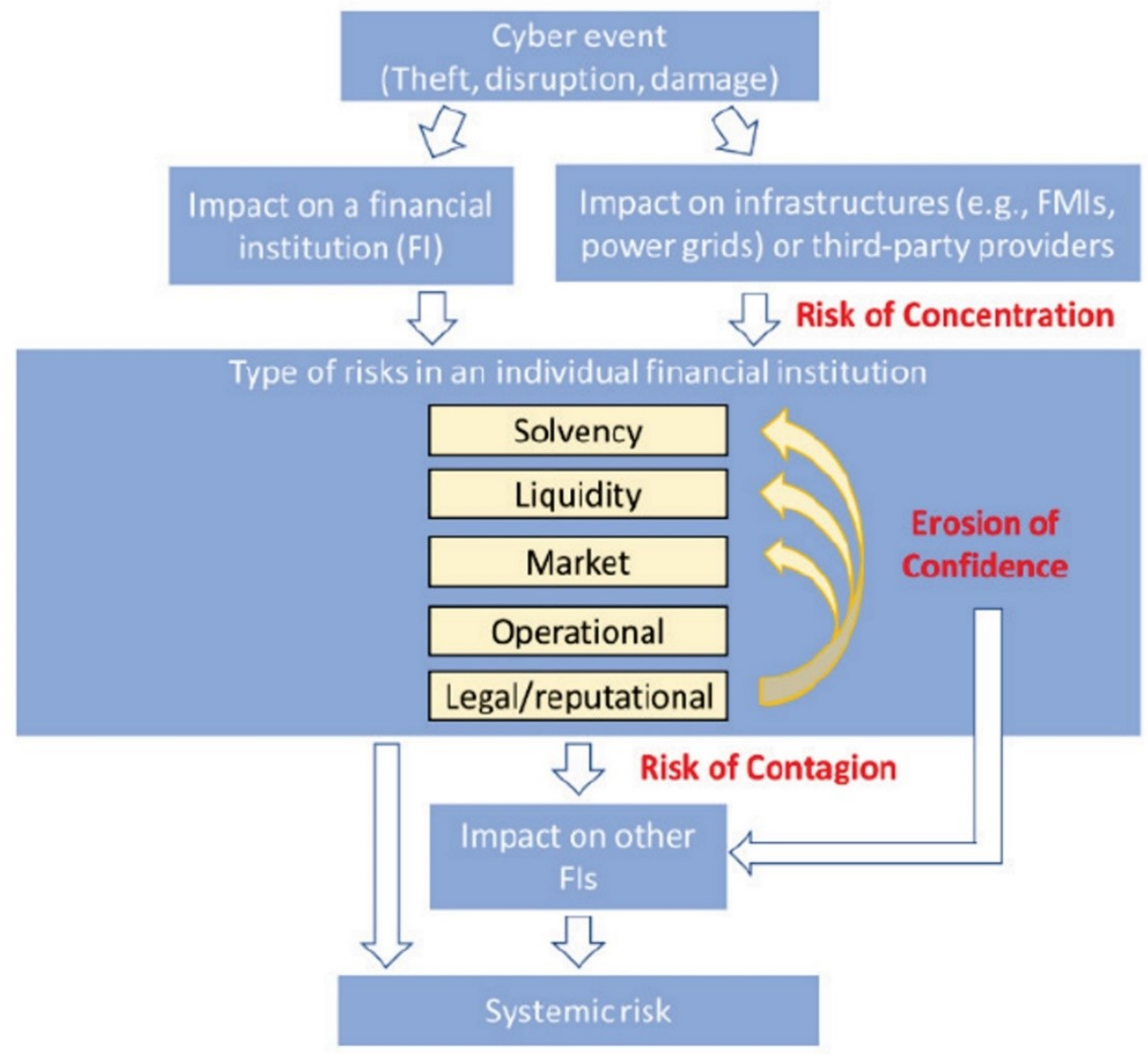

Figure 7. Cyber risk and systemic risk (Source: IMF, 2020, p.9)

According to its rules, data subjects must be given the opportunity to give clear consent prior to the collection of personal data. Organizations are required to notify supervisory authorities and data subjects within 72 hours in the event of a data breach affecting users' personal information in most cases.

Data subjects must be notified of their rights with regard to their personal data, including the right to access, correct, and delete personal information. The regulation establishes new important rights for individuals, like data portability, the right not to be profiled, or the right to be forgotten.

\section{Financial innovations and consumer protection}

From the financial consumers' point of view, FinTech based financial innovations are, in the first instance, transforming the way they interact and access financial market. They enable better access to financial services and enhance financial inclusion process (Consumers International, 2017). They also change the ways consumers are interacting with financial services providers. It is shifted to online channels and frequently to e-money, with particular application of mobile devices like smartphones and feature phones. It also includes the use of non-incumbent, 
new market players to satisfy the consumers' needs better, expanding competition and market choice.

With the rise of FinTech retail, financial market is increasingly demonetized and mobile wallets are gaining in importance.

FinTech is offering different applications that also increase consumers' awareness of their financial activities. It provides, for example, means for analyzing personal incomes and expenditures using consolidated data coming from various sources and all of users' account providers in one place. It may additionally offer a PowerPoint presentation of this numerical analysis. In effect, it may play the role of automated personal financial advisor.

FinTech is bringing to consumers not only opportunities and pleasures, but also new risks, concerns, and consumer protection challenges. Key among them are data and privacy protection, management of cybercrime, fight against financial inclusion, questions of liability, and systemic risk.

As a data-intensive ecosystem, FinTech alert security concerns with respect to hacking and data breaches, identity theft, and theft of assets. As financial institutions are increasing the amount and variety of data they possess, ownership and control of data will become a key issue for all stakeholders. Data security will play a fundamental role in maintaining trust with the financial institutions and in the development of new business models.

It is, therefore, very natural that the issue has recently become a global theme. In its recent document, the G20/OECD Task Force on Financial Consumer Protection is offering financial consumers' protection global guidelines in the context of digital financial services (DFS; G20/OECD, 2018). They define DFS as "financial operations using digital technology, including electronic money, mobile financial services, on line financial services, e-teller and branchless banking, whether through bank or non-bank institutions. DFS can encompass various monetary transactions such as depositing, withdrawing, sending and receiving money, as well as other financial products and services, including payment, credit, saving, pensions and insurance. DFS can also include non-transactional services, such as viewing personal financial information through digital devices" (G20/OECD, 2018, p.13).
Additionally, the guidelines also define the major risks of DFS. They see them in four main areas:

- Market-driven risks: These may include, inter alia, a misuse of unfamiliar products, offers delivered to uninformed and unprepared consumers, new types of market fraud, lack of security and privacy of data, excessive use of digital profiling to exclude, inter alia, unwanted customers, rapid access to high-cost credit, and distribution of speculative products.

- Technology-driven risks: These may include misuse of small and big data, unreliability of mobile networks and digital finance platforms, cybersecurity risks, excessive use of algorithms affecting financial decisions in an inappropriate manner, or implying wrong correlations.

- Consumer-driven risks: These may include increased digitalization of daily life and personal financial decisions not necessarily matched by adequate financial literacy levels, greediness of financial institutions.

- Regulation- and supervision-driven risks: These may encompass, inter alia, inadequate disclosure or redress mechanisms, existence of regulatory arbitrage, missing coordination arrangements of supervisory bodies concerned, etc.

If these problems can be properly resolved, FinTech's new opportunities will deliver great potential in providing financial services tailored to the needs and preferences of consumers and that are available through mobile devices.

\section{Concluding remarks}

As indicated in our analysis, financial systems worldwide are increasingly experiencing the mounting pressure of the new technology-based financial innovations. Some of these developments are generating alternative financial reality existing parallelly to the "old" one, whereas some of them are replacing the "old" one. Alternative intermediating institutions are gaining ground vis-à-vis incumbents, relying on their technological and market supremacy. Some technological solutions provide, on the other hand, for the disintermediation of finance, thus removing unnecessary transaction costs and matching directly economic agents. Digitalization and datafication, cou- 
pled with artificial intelligence, are offering new immense operational opportunities and economic benefits. On the other hand, they are also the source of new risks to the financial and economic systems, which need to be properly addressed.

Technology-based innovations in the private financial systems are accompanied by numerous innovative developments in the public sector: regulations, supervision, monetary systems, tax collection systems, critical financial infrastructure, etc. We have not focused on this, but it is obvious that the two parts of the financial systems must be in equilibrium in order to be able to communicate with the help of financial instruments.

\section{References}

[1] Beck, T., Chen, T., Lin, Ch., Song, F.M., 2012. Financial Innovation: The Bright and the Dark Sides. Working Paper, No. 52012, Hong Kong Institute for Monetary Research.

[2] BIS, 1986. Recent Innovations in International Banking (Cross Report). Prepared by a Study Group Established by the Central Banks of the Group 10 Countries. CGFS Papers No 1.

[3] BIS, 2017. Sound Practices: Implications of Fintech for Developments for Banks and Bank Supervisors. BCBS (Basel Committee on Banking Supervision).

[4] BIS, 2019. Shin H.S., 2019. Bigtech in Finance: Opportunities and Risks, Annual Economic Report.

[5] BIS, 2019a. Borio, C., 2019. Central Banking in Challenging Times.

[6] BIS, 2020 (May). Aldasoro, I., Gambacorta, L., Giudici, P., and Leach, T., 2020. The Drivers of Systemic Risk. BIS Working Papers No 865.

[7] BIS, 2020. Ehrentraud, J., Ocampo, D.G., Garzoni, L., and Piccolo, M., Responses to Fintech: A Cross-Country Overview.

[8] Brummer, Ch., Yadav, Y., 2017. The Fintech Trilemma. Georgetown University Law Centre, Draft.

[9] Brunnermeier, M.K., 2009. Deciphering the Liquidity and Credit Crunch 2007-2008. Journal of Economic Perspectives, 23, pp.77-100.
[10] Buckley, R.P., Arner, D.W., Zetsche, D.A., Selga., E., 2019. The Dark Side of Digital Financial Transformation: the New Risks of FinTech and the Rise of TechRisk. European Banking Institute (EBI) Working Paper 2019/54.

[11] Calomiris, Ch.W., 2009. Financial Innovation, Regulation and Reform. Cato Journal, 29 (1), pp.65-91.

[12] Consumers International, 2017. Banking on the Future: An Exploration of Fintech and the Consumer Interest.

[13] EBA, 2020. EBA Report on Big Data and Advanced Analytics. EBA/REP/2020/01.

[14] Eiopa, 2019. Big Data Analytics in Motor and Health Insurance: A Thematic Review.

[15] EU Monitor, 2020 (March). Deutsche Bank. Digital Economy and Structural Change.

[16] European Parliament, 2018 (July). Competition Issues in the Area of Financial Technology (FinTech). ECON Cmmittee.

[17] FSB, 2017. Financial Stability Implications from FinTech. Supervisory and Regulatory Issues that Merit Attention.

[18] FSB, 2019. BigTech in Finance. Market Developments and Financial Stability Implications.

[19] FSB, 2019a. Decentralized Financial Technologies. Report on Stability, Regulatory and Governance Implications.

[20] G20, 2011. High Level Principles on Financial Consumer Protection. OECD.

[21] G20/OECD, 2018. Policy Guidelines on Financial Consumer Protection Approaches in the Digital Age.

[22] Gandhi, P., Khanna, S., Ramaswamy, S., 2016. Which Industries are the Most Digital (And Why)? Harvard Business Review, April.

[23] Gasiorkiewicz, L., Monkiewicz, J. (eds), 2021. Innovation in financial services. Balancing private and public interests. London - New York: Routledge (forthcoming).

[24] Halliasos, M. (ed.), Shiller, R.J., Barberis, N.C., Campbell, J.Y., Viceira, L.M., 2013. Financial Innovation: Too Much or Too Little? Cambridge, US: MIT Press.

[25] Henderson, B.J., Pearson, N.D., 2011. The Dark Side of Financial Innovation: A Case Study of the Pricing of a Retail Financial Product. Journal of Financial Economics, 100 (2), pp.227-247. 
[26] IMF, 2020. Goh, J., Kang, H., Koh, Z.X, Lim, J.W, Ng, Ch.W. Sher, G., Yao, Ch., 2020. Cyber Risk Surveillance: A Case Study Of Singapore. IMF Working Paper No. 20/28.

[27] Kabza, M., 2020. Sztuczna inteligencja w usługach finansowych (Artificial intelligence in financial services). In: Gąsiorkiewicz, L., Monkiewicz, J., eds., 2020. Innowacje na rynkach finansowych (Innovations in Financial Markets). Warszawa: Oficyna Wydawnicza PW, pp.128-153.

[28] Lippel., S., 2019. Decentralized Finance Is a Continuum. Facebook Twitter, March 5.

[29] Mishra, K.P., 2008. Financial Innovations in Economic Growth - A Theoretical Approach. SSRN: https://ssrn.com/abstract=1262658.

[30] Ng, F. and Kandaswamy, R., 2017. Market Insight: Value-Based Cloud Opportunities in Financial Services. Gartner Research, ID: G00324426.
[31] Oslo Manual, 2018. The Measurement of Scientific, Technological and Innovation Activities. Paris: OECD European Union.

[32] Schumpeter, J., 1934 (2008). The Theory of Economic Development: An Inquiry Into Profits, Capital, Credit, Interest, and the Business Cycle. Brunswick (U.S.A) and London (U.K.): Transaction Publishers.

[33] Shirai, S., 2019. Money and Central Bank Digital Currency. ADBI Working Paper Series, No. 922. Tokyo: Asian Development Bank Institute.

[34] U.S. Department of Treasury, 2018. A Financial System that Creates Opportunities. Report to the President Donald J. Trump.

[35] World Economic Forum, 2012. Rethinkig Financial Innovation. Reducing Negative Outcomes While Retaining benefits. A World Economic Forum Report in collaboration with Oliver Wyman. 